\title{
Estimates of source parameters of $M 4.9$ Kharsali earthquake using waveform modelling
}

\author{
AJAY PAUL* and NARESH KUMAR \\ Wadia Institute of Himalayan Geology, Dehradun 248 001, India. \\ *e-mail: ajaypaul@wihg.res.in
}

\begin{abstract}
This paper presents the computation of time series of the 22 July $2007 M 4.9$ Kharsali earthquake. It occurred close to the Main Central Thrust (MCT) where seismic gap exists. The main shock and 17 aftershocks were located by closely spaced eleven seismograph stations in a network that involved VSAT based real-time seismic monitoring. The largest aftershock of $M 3.5$ and other aftershocks occurred within a small volume of $4 \times 4 \mathrm{~km}$ horizontal extent and between depths of 10 and $14 \mathrm{~km}$. The values of seismic moment $\left(M_{o}\right)$ determined using P-wave spectra and Brune's model based on $f^{2}$ spectral shape ranges from $10^{18}$ to $10^{23}$ dyne-cm. The initial aftershocks occurred at greater depth compared to the later aftershocks. The time series of ground motion have been computed for recording sites using geometric ray theory and Green's function approach. The method for computing time series consists in integrating the far-field contributions of Green's function for a number of distributed point source. The generated waveforms have been compared with the observed ones. It has been inferred that the Kharsali earthquake occurred due to a northerly dipping low angle thrust fault at a depth of $14 \mathrm{~km}$ taking strike $\mathrm{N} 279^{\circ} \mathrm{E}$, dip $14^{\circ}$ and rake $117^{\circ}$. There are two regions on the fault surface which have larger slip amplitudes (asperities) and the rupture which has been considered as circular in nature initiated from the asperity at a greater depth shifting gradually upwards. The two asperities cover only $10 \%$ of the total area of the causative fault plane. However, detailed seismic imaging of these two asperities can be corroborated with structural heterogeneities associated with causative fault to understand how seismogenesis is influenced by strong or weak structural barriers in the region.
\end{abstract}

\section{Introduction}

The Himalaya is the product of collision of Indian and Eurasian plates (Dewey and Bird 1970; Zhao et al 1993). At present the Indian plate is underthrusting beneath the Eurasian plate. The elastic strain energy built due to the plate movement is a continuous process which resulted in the occurrence of four great earthquakes in the last one hundred and twenty years in the Indian region (1897 Shilong, 1905 Kangra, 1934 Bihar-Nepal, 1950 Assam) but no great earthquake has occurred in the Garhwal-Kumaun region. This section of Himalayan arc between the ruptured zones of Kangra earthquake and Bihar-Nepal earthquake has been recognized as seismic gap (figure 1) and it has been interpreted to have accumulated potential slip for generating future great earthquakes (Khattri and Tyagi 1983). On 22 July 2007 a moderate earthquake $\left(M_{L} 4.9\right)$ occurred near Kharsali in this seismic gap region (figure 1) where two moderate earthquakes had occurred in the recent past at an interval of $8 \mathrm{yrs}$ (19 October 1991, Uttarkashi earthquake $-M_{L} 6.5$ and 29 March 1999, Chamoli earthquake $-M_{L}$ 6.6). The 2007 Kharsali earthquake was recorded by recently established VSAT connected eleven station broadband network. Studies have been carried out on the recorded time series data and the modelling results are compared with the synthetic time series.

Keywords. Green's function; near field; Himalaya. 


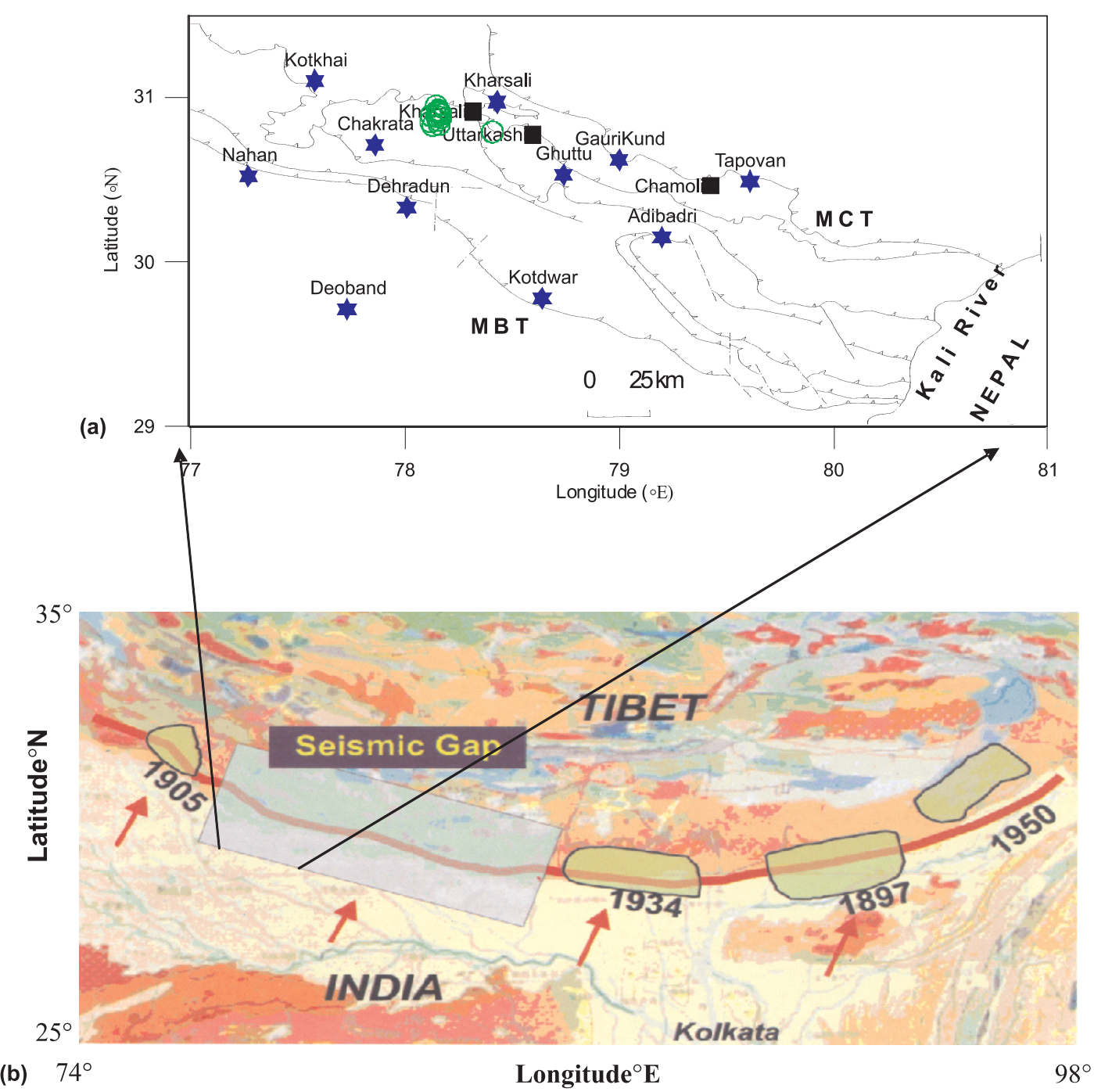

Figure 1. (a) Tectonic map of the region (after Valdiya 1981) showing seismic stations ( $\star$ ) and epicentral locations of moderate earthquakes (-) Kharsali (2007), Chamoli (1999), Uttarkashi (1991) and aftershocks of Kharsali earthquake (o). (b) Four great earthquakes along the Himalayan arc (Richter 1958).

Detailed analysis of time series data recorded during an earthquake helps in understanding the physics of the earthquake source which is quite complicated and cumbersome to work out. The faulting process may be highly inhomogeneous. The distribution of slip over the fault can vary both in magnitude and direction (Mikumo and Miyatake 1987; Wald et al 1991). There are regions on the fault where large slip might occur which corresponds to asperities. Some details of this variability of slip distribution over the fault plane can be inferred from modelling of ground motion data.

The earliest and most fundamental synthesis of ground motion was carried out by Keiiti (1968) and Haskell (1969) based on Green's function approach. The response of horizontally layered crustal structure to a double couple point source has been computed using a number of techniques. The work was further carried out by different researchers using different sets of waveform data (Khattri et al 1994; Yu et al 1995; Ichinose et al 1997; Paul and Pant 2003; Singh and Mittal 2005).

The generation of synthetic seismograms helps in estimating several critical parameters, such as location of a point of initiation of rupture, rupture velocity, rise time and distribution of slip amplitude on the fault, which are considered rigorously during analysis.

In the present work, the generation of synthetic seismograms in the near field is based on dislocation moving over a fault plane. Nature of rupture propagation over the fault plane, radiation pattern effects, presence of free surface layering in the earth between the source and free surface and effect of finite moving source are some 
of the key fault features considered for waveform generation.

\section{Geology and tectonics of the region}

Sandwiched between the Main Boundary Thrust (MBT) in the south and Main Central Thrust (MCT) in the north, the Garhwal-Kumaun Hills are structurally very complex and ecologically sensitive. Geologically the rocks in this region constitute the southeastern terminus of the Krol belt (Auden 1934; Heim and Gansser 1939; Valdiya 1988). The Krol belt in GarhwalKumaun Hills comprises the Jaunsar and Krol group in an ascending order of succession. The Nagthat formation made up of thick succession of Quartzarenite associated with penecontemporaneous mafic lava flows constitutes the lowermost litho unit in the area. There are two major sets of active northward dipping thrusts MCT and MBT. Along these thrusts, slabs of the subducting Indian plate have piled southward. These thrusts form the boundaries of geological subprovinces having characteristic geology and physiography (Gansser 1964). Along the MCT, the crystallines of the Higher Himalaya (Precambrian) are overthrusted southward and have overridden the metasedimentary formations (Paleozoic) of the lesser Himalaya. These formations of Lesser Himalaya have overridden the mollasic Shiwalik (Cenozoic) sedimentary formations of the outer Himalaya along the MBT. The formations just to the north of MBT are highly folded and thrusted.

The slopes of the region are steep. The disposition of various discontinuities including bedding and cleavages and joints with respect to the slope is such that the slopes lie in a critical state and even minor changes in the topographic configuration either by man or natural processes may trigger mass movement leading to disastrous consequences. The creep of slopes during rains is one such example. It is significant to note that the region has a past history of major catastrophe and a vast area is covered with debris fans of old landslides that are still in the process of stabilization. Therefore even a small magnitude may cause great damage to life and property. The area is characterized by high seismicity. Figure 1 shows the tectonic setup of the region. Genesis of earthquakes in this region may be attributed to the strain generated by the convergence of the Indian and the Eurasian plate.

The Indian plate is moving at a rate of $5 \mathrm{~cm} / \mathrm{yr}$ relative to the Eurasian plate in a northeasterly direction (Yu et al 1995). The highest seismic activity is confined to a narrow zone which follows the Himalayan trend and lies south of surface trace of the MCT. The foci of most of the earthquakes in this zone lie in the upper $20 \mathrm{~km}$ of the crust (Ni and Barazangi 1984). The fault plane solutions are mostly of thrust type with the P-axis normal to the trend of the Himalayan arc. One of the nodal planes in most of the fault plane solutions is shallow dipping towards the northeast, which is confirmable with conformity with the surface geological evidence for thrusting (Yu et al 1995).

Seismic studies based on microearthquake recording using local networks have also shown that belt of local seismicity lies to the south of the MCT in a local region. The composite fault plane solutions based on these microearthquake studies show thrust as well as strike slip mechanism (Khattri 1992a, 1992b).

\section{Data and instrumentation}

Recently, Wadia Institute of Himalayan Geology (WIHG), Dehradun, India has established a total of eleven broadband seismic stations (Dehradun, Tapovan, Adibadri, Gaurikund, Ghuttu, Deoban, Kotdwar, Chakrata and Kharsali in Uttaranchal and Nahan and Kotkhai in Himachal Pradesh) in the NW Himalaya region which have been connected through VSAT telemetry network. This network acquires the seismic data in continuous real mode at Central Recording Station, Dehradun. The upgraded VSAT linked seismic network is equipped with broadband seismometers (Trillium 240) and Taurus digital data acquisition system. The ground velocity data are recorded in broad frequency band at the rate of 100 sps.

In the present work, the high quality digital data of VSAT linked broadband stations (figure 1) has been processed to obtain both kinematic and dynamic source parameters of Kharsali earthquake and its aftershock activity.

\section{Methodology - synthetic seismogram}

The methodology to compute the synthetic accelerograms is based on a dislocation moving over a fault plane using Green's function approach (Aki and Richards 1980). First, the source is characterized which extends over a finite area (the fault plane) and over a finite amount of time. The rupture process produces dislocations over the fault which varies both in direction and magnitude. The displacement produced by such a realistic source model can be synthesized from a far field radiation using a point double couple source. Although in the near field of a large earthquake, the dimensions of the source cannot be ignored but in the present work, the fault area is divided into a 
number of subfaults which can be approximated as point source with area much smaller than the distance to the observation point. Under such assumption, ground motion can be computed using far field radiation from a point double couple source. The radiation pattern has been expressed in terms of fault parameters slip $(u)$, rake $(\lambda)$, strike of the fault $\left(\varphi_{s}\right)$, dip $(\delta)$ and take off angle $\left(i_{0}\right)$. Following are the formulation used for evaluating displacement (Keiiti and Richards 1980):

$$
\begin{gathered}
\mathbf{u}^{P}(\mathbf{x}, t)=\left(M_{o} R^{P} / 4 \pi \rho \alpha^{3} r\right) f(t-r / \alpha) \mathbf{e}_{p}, \\
\mathbf{u}^{S V}(\mathbf{x}, t)=\left(M_{o} R^{S V} / 4 \pi \rho \beta^{3} r\right) f(t-r / \beta) \mathbf{e}_{s}, \\
\mathbf{u}^{S H}(\mathbf{x}, t)=\left(M_{o} R^{S H} / 4 \pi \rho \beta^{3} r\right) f(t-r / \beta) \mathbf{e}_{t},
\end{gathered}
$$

where $\mathbf{e}_{p}, \mathbf{e}_{s}, \mathbf{e}_{t}$ are unit vectors in the direction of particle motion in the $\mathrm{P}-\mathrm{S}$ S- and $\mathrm{SH}$-wave, respectively. $\mathbf{u}^{P}(\mathbf{x}, t), \mathbf{u}^{S V}(\mathbf{x}, t)$ and $\mathbf{u}^{S H}(\mathbf{x}, t)$ are displacement due to $\mathrm{P}-, \mathrm{SV}$ - and $\mathrm{SH}$-wave, respectively. $\alpha$ and $\beta$ are the $\mathrm{P}$ - and S-wave velocity, respectively, $r$ is hypocentral distance, $\rho$ is density of medium, $f(t-r / a)$ is source time function for $\mathrm{P}$-wave, $f(t-r / \beta)$ is source time function for S-wave, $M_{o}$ is seismic moment, $R^{P}, R^{S V}$ and $R^{S H}$ are the radiation pattern term for $\mathrm{P}-, \mathrm{SV}$ - and $\mathrm{SH}$-waves, respectively.

The formulations for radiation pattern terms used in the present work are:

$$
\begin{aligned}
R^{P}= & \cos \lambda \sin \delta \sin ^{2} i_{0} \sin 2\left(\phi_{-} \phi_{s}\right) \\
& +\sin \lambda \cos 2 \delta \sin 2 i_{0} \sin \left(\phi_{-} \phi_{s}\right) \\
& +\sin \lambda \sin 2 \delta\left[\begin{array}{ll}
\cos ^{2} i_{0}-\sin ^{2} i_{0} \sin ^{2}\left(\phi_{-} \phi_{s}\right)
\end{array}\right] \\
& -\cos \lambda \cos \delta \sin 2 i_{0} \cos \left(\phi_{-} \phi_{s}\right), \\
R^{S V}= & +1 / 2\left(\cos \lambda \sin \delta \sin 2 i_{0}\right) \sin 2\left(\phi_{-} \phi_{s}\right) \\
& +\sin \lambda \cos 2 \delta \cos 2 i_{0} \sin \left(\phi_{-} \phi_{s}\right) \\
& -1 / 2 \sin \lambda \sin 2 \delta \sin 2 i_{0}\left[1+\sin ^{2}\left(\phi-\phi_{s}\right)\right] \\
& -\cos \lambda \cos \delta \cos 2 i_{0} \cos \left(\phi-\phi_{s}\right), \\
R^{S H}= & \cos \lambda \sin \delta \sin i_{0} \cos 2\left(\phi-\phi_{s}\right) \\
& +\sin \lambda \cos 2 \delta \cos i_{0} \cos 2\left(\phi-\phi_{s}\right) \\
& -1 / 2 \sin \lambda \sin 2 \delta \sin i_{0} \sin 2\left(\phi-\phi_{s}\right) \\
& +\cos \lambda \cos \delta \cos i_{0} \sin \left(\phi-\phi_{s}\right),
\end{aligned}
$$

where $\phi$ is the azimuth. To obtain the ground motion in a finite medium the above formulations are modified for free surface effect as follows:

$$
\begin{aligned}
\mathbf{u}^{P} & =u_{H}^{P} \cos \phi \mathbf{e}_{1}+u_{H}^{P} \sin \phi \mathbf{e}_{2}+u_{3}^{P} \mathbf{e}_{3}, \\
\mathbf{u}^{S V} & =u_{H}^{S V} \cos \varphi \mathbf{e}_{1}+u_{H}^{S V} \sin \phi \mathbf{e}_{2}+u_{3}^{S V} \mathbf{e}_{3}, \\
\mathbf{u}^{S H} & =-C \sin +C \cos \phi
\end{aligned}
$$

where $C$ is the amplitude of the $\mathrm{SH}$ waves in an infinite medium. For a moving source the effect of rupture propagation has been taken. The delay time $(\tau)$ taken to move the radiation point from one subfault to another is evaluated and the final expression for far field displacement due to a finite moving source is given by:

$$
\begin{aligned}
u(\mathbf{x}, t)= & \left(M_{o} R^{P} / 4 \pi \rho \alpha^{3} r \tau_{\alpha}\left\{f\left[t-\left(r_{o} / \alpha\right)\right]\right.\right. \\
& \left.\left.-f\left[t-\left(r_{o} / \alpha\right)-\tau_{\alpha}\right]\right\}\right) \\
& +\left(M_{o} R^{S V} / 4 \pi \rho \alpha^{3} r \tau_{\beta}\left\{f\left[t-\left(r_{o} / \beta\right)\right]\right.\right. \\
& \left.\left.-f\left[t-\left(r_{o} / \beta\right)-\tau_{\beta}\right]\right\}\right) \\
& +\left(M_{o} R^{S H} / 4 \pi \rho \alpha^{3} r \tau_{\beta}\left\{f\left[t-\left(r_{o} / \beta\right)\right]\right.\right. \\
& \left.\left.-f\left[t-\left(r_{o} / \beta\right)-\tau_{\beta}\right]\right\}\right),
\end{aligned}
$$

where $M_{o}, R^{S H}, R^{S V}, R^{P}, \rho, \alpha, r, \tau_{\alpha}$ are the seismic moment, radiation pattern due to $\mathrm{SH}$, $\mathrm{SV}$ and $\mathrm{P}$ wave, density of the medium, $\mathrm{P}$ wave velocity, hypocentral distance and delay time taken by $\mathrm{P}$ wave, respectively. The wave field given by this equation is then corrected for free surface effect using equations (7-9). It has been found that location of point of initiation of rupture, rupture velocity, rise time and distribution of slip amplitude on the fault are the most critical parameters in generation of synthetic seismograms.

\section{Computation of synthetic waveform}

For the purpose of simulation, a source model has been specified which includes spatio-temporal parameters of earthquake focus, fault geometry, slip distribution over the fault plane and source time function. The fault plane chosen for modelling of ground motion is assumed to be buried in a homogenous half space.

The velocity model considered is the two layered P-velocity model derived from the local earthquake 
surveys (Khattri 1992a) with $\mathrm{P}$ wave velocity of $5.2 \mathrm{~km} / \mathrm{s}$ in the first layer and $6.0 \mathrm{~km} / \mathrm{s}$ in the second layer with the density of half space $2.7 \mathrm{~g} / \mathrm{cm}^{3}$. These velocities correspond to a material with Poisson's ratio of 0.25 which signifies that half space is made up of well consolidated rocks. The source time function used in the present work is the ramp function with rounded shoulders (Ben-Menahem and Singh 1981):

$$
F(t)= \begin{cases}0, & t \leq 0 \\ \left(t / T_{o} / \omega_{o} t\right), & 0 \leq t \leq T_{o} \\ 1, & t \leq T_{o}\end{cases}
$$

where $T_{o}$ is the rise time and $\omega_{o}=2 \pi / T_{o}$. This function is continuous everywhere and is easily differentiable. The above form is chosen to model slip as a function of time at a point on the fault. For generating synthetic seismograms in the near field geometry, the size of the source, i.e., the fault plane is carefully specified. The fault is considered to be made of a number of subfaults each of size $1 \times 1 \mathrm{~km}$.

The variation in slip amount in each subfault is estimated from the amplitude variation in the observed time series coupled with the rupture prorogation model on the fault. The observed time series gives the variation of amplitude with time. The location and number of grids contributing to the corresponding amplitude depends on rupture propagation model. The rupture propagation model used in the present study consists of rupture starting from a single point (i.e., the hypocenter) and then spreading all over the fault in the form of circular rupture fronts for both $\mathrm{P}$ and S-waves. The equal time contours (isochrones) are drawn at an interval of one second. The contours join all those points on the fault plain from which the total travel time of $\mathrm{P}$ (or $\mathrm{S}$ ) wave is the same. This total travel time consists of time of rupture propagation from hypocenter to a point on the fault at the velocity of rupture propagation $v_{r}$ and the time taken at the $\mathrm{P}$ (or $\mathrm{S}$ ) wave velocity from that point on the fault to the recording station. All subfaults through which the contours pass contribute to waveform on the synthetic time series at the same instant of time.

The slight difference in amplitude of pulse shape is also contributed by the each subfault on a given contour by virtue of different geometric attenuation, radiation pattern contribution and free surface effect. The direction of slip vector is kept constant in each subfault.

The coordinates of epicenter and station location are available in terms of their latitudes and longitudes. These were converted into Cartesian co-ordinates $x_{1}$ and $x_{2}$ with epicenter as origin, $x_{1}$ positive towards north and $x_{2}$ positive towards east. The third coordinate $x_{3}$ is taken positive downward. All the stations are considered to be situated on the same elevation as the epicenter (above sea level) and the difference between the station elevations were ignored. Following formulae given by Lee and Stewart (1981) were used to obtain coordinates of stations on $x_{1}-x_{2}$ planes:

$$
\begin{aligned}
& x_{1}=60 A\left(\lambda-\lambda_{o}\right), \\
& x_{2}=60 B\left(\varnothing-\varnothing_{o}\right),
\end{aligned}
$$

where $\lambda$ and $\varnothing$ are the longitude and latitude of the station and $\lambda_{o}$ and $\varnothing_{o}$ are the longitude and latitude of the epicenter in the equations, respectively. The values for $A$ and $B$ in these equations are obtained as follows:

$$
\begin{aligned}
A= & 1.8553654+0.0062792 \sin ^{2} \Phi \\
& +0.0000319 \sin ^{4} \Phi, \\
B= & 1.8428071+0.0187098 \sin ^{2} \Phi \\
& +0.0001583 \sin ^{4} \Phi,
\end{aligned}
$$

where $\Phi=1 / 2\left(\varnothing+\varnothing_{o}\right)$.

In this study, a local (i.e., fault based) coordinate system $\left(y_{1}, y_{2}, y_{3}\right)$ was chosen in the following manner. The focus which lies on the footwall side of the fault is chosen as the origin. A line on the fault plane parallel to strike of the fault is chosen as the $y_{1}$-axis with $y_{2}$-axis in the up dip direction and perpendicular to the $y_{1}$-axis. The $y_{3}$-axis is chosen perpendicular to the fault plane and penetrating the hanging wall. Figure 2 shows the local co-ordinate systems on a fault with $\varnothing_{s}$ as strike angle and $\delta$ as the angle of dip. The tangent to the seismic ray makes an angle $i_{o}$ at the focus. The line joining the origin to the recording station makes an angle of $\varnothing$ with the $x_{1}$-axis.

\section{Spectral analysis and source parameters}

The source model relates the corner frequency and low frequency asymptote to source dimension and seismic moment (Brune 1970). Observations of spectra consistent with Brune's theory have been reported for large earthquakes (Hanks and Wyss 1972; Wyss and Hanks 1972; Ichinose et al 1997) in 


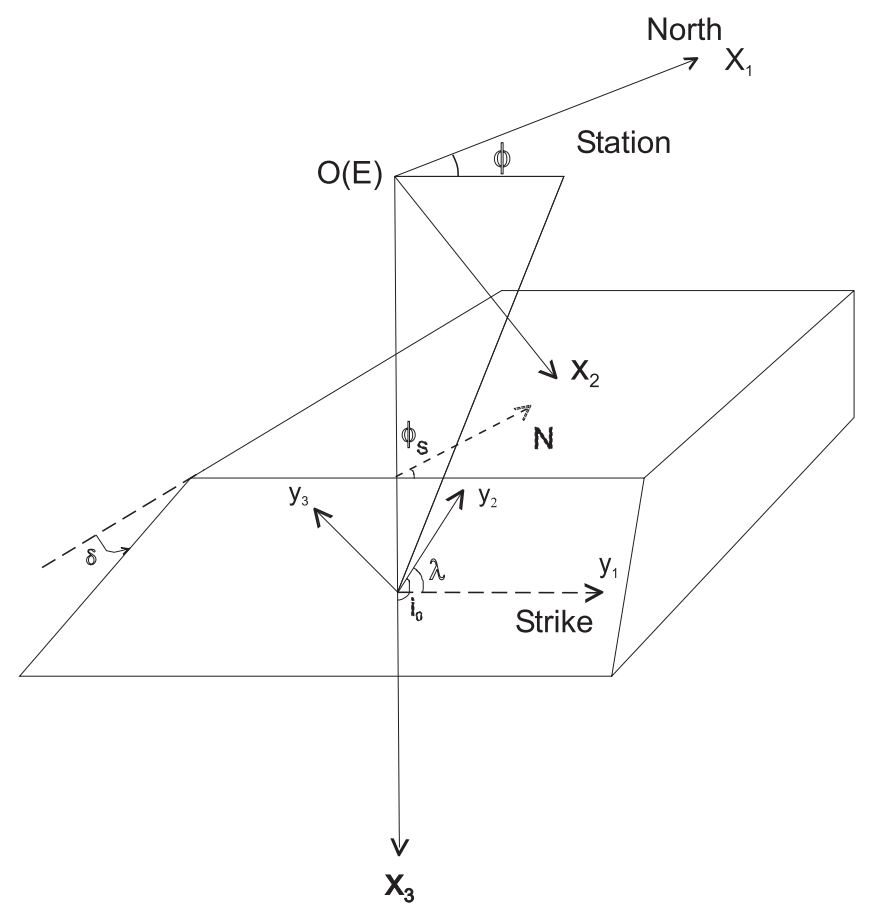

Figure 2. Local and global co-ordinates co-ordinate systems on a fault $\left(\phi_{s}\right.$ : strike angle, $\delta$ : angle of dip, $\lambda$ : slip angle, $\mathrm{O}(\mathrm{E})$ : epicenter, $i_{o}$ : take off angle, $\phi$ azimuth. $Y_{1}, Y_{2}$ and $Y_{3}$ are local co-ordinates and $X_{1}, X_{2}$ and $X_{3}$ are global co-ordinates.

addition to micro-earthquakes (Douglas and Ryall 1972; Kumar et al 2006) thus covering a very wide range of computed values for source parameters based on the theory.
A time window of $4 \mathrm{~s}$ (sampling rate 100 samples per second) was applied from the start of $\mathrm{P}$ wave to compute $\mathrm{P}$-wave spectra. This has been done to exclude S-wave effects. After conversion of velocity to displacement in the Fourier domain, the spectral parameters, i.e., $f_{c}$ and $\Omega_{o}$ are estimated. The physical parameters, i.e., seismic moments and stress drops, were then computed from the spectral analysis of the recorded data using Brune's model (Kellis-Borok 1959; Brune 1970; Sharma and Wason 1994). The formulations used for the purpose were as follows:

$$
\begin{aligned}
M o & =4 \pi \rho v^{3} D \Omega_{o} / R \\
r & =2.34 v / 2 \pi f c \\
\Delta \sigma & =7 M_{o} / 16 r^{3}
\end{aligned}
$$

where, $M_{o}, \rho, v, r, f_{c}, \Delta \sigma, D, \Omega_{o}$ and $R$ denote seismic moment, density, velocity, source radius, corner frequency, stress drop, epicentral distance, spectral amplitude and radiation pattern, respectively. The above formulations are widely used to compute the source parameters. The radiation pattern $R$ was approximately taken to be $85 \%$ (Prochazkova 1980). $M_{o}$ was taken as the average of seismic moments computed from different recording stations for the event. The estimated values for the seismic moments and the stress drops are given in table 1 .

Table 1. Hypocentral and source parameters of the main shock and aftershocks obtained from P-wave displacement spectra using Brune's circular model.

\begin{tabular}{rccccccccc}
\hline $\begin{array}{c}\text { Sl. } \\
\text { no. }\end{array}$ & Date & Time & Latitude & Longitude & Depth & $M_{L}$ & $\begin{array}{c}\text { Seismic } \\
\text { moment }\end{array}$ & $\begin{array}{c}\text { Source } \\
\text { radius } \\
(r) \mathrm{m}\end{array}$ & $\begin{array}{c}\text { Stress } \\
\text { drop } \\
(\Delta \sigma) \text { bars }\end{array}$ \\
\hline 1 & $7 / 22 / 2007$ & $23: 02: 13.3$ & 30.90 & 78.31 & 14 & 4.9 & $4.16 \times 10 \mathrm{e} 16$ & 2110 & 41.5 \\
2 & $7 / 22 / 2007$ & $23: 05: 51.2$ & 30.94 & 78.35 & 10.8 & 2.3 & $6.6 \times 10 \mathrm{e} 14$ & 540 & 18.3 \\
3 & $7 / 22 / 2007$ & $23: 07: 50.6$ & 30.83 & 78.32 & 8.9 & 2.0 & $2.2 \times 10 \mathrm{e} 14$ & 673 & 3.2 \\
4 & $7 / 22 / 2007$ & $23: 09: 26.3$ & 30.93 & 78.23 & 10.1 & 1.9 & $2.9 \times 10 \mathrm{e} 14$ & 474 & 12.2 \\
5 & $7 / 22 / 2007$ & $23: 12: 08.4$ & 30.91 & 78.31 & 11.2 & 1.8 & $2.4 \times 10 \mathrm{e} 14$ & 510 & 7.9 \\
6 & $7 / 22 / 2007$ & $23: 12: 50.5$ & 30.94 & 78.27 & 10.2 & 2.0 & $3.2 \times 10 \mathrm{e} 14$ & 492 & 9.8 \\
7 & $7 / 22 / 2007$ & $23: 25: 16.8$ & 30.81 & 78.29 & 10.1 & 2.2 & $1.5 \times 10 \mathrm{e} 14$ & 596 & 3.1 \\
8 & $7 / 22 / 2007$ & $23: 38: 52.6$ & 30.91 & 78.31 & 4.9 & 2.3 & $2.2 \times 10 \mathrm{e} 13$ & 465 & 1 \\
9 & $7 / 22 / 2007$ & $23: 45: 07.1$ & 30.84 & 78.27 & 11.9 & 2.3 & $6.6 \times 10 \mathrm{e} 13$ & 588 & 1.5 \\
10 & $7 / 22 / 2007$ & $23: 57: 53.6$ & 30.87 & 78.27 & 11.8 & 2.2 & $8.0 \times 10 \mathrm{e} 14$ & 494 & 29.7 \\
11 & $7 / 22 / 2007$ & $05: 39: 17.9$ & 30.89 & 78.29 & 10.3 & 2.4 & $2.3 \times 10 \mathrm{e} 14$ & 352 & 7.6 \\
12 & $7 / 22 / 2007$ & $06: 33: 20.3$ & 30.86 & 78.25 & 9.2 & 2.2 & $1.7 \times 10 \mathrm{e} 14$ & 460 & 6 \\
13 & $7 / 23 / 2007$ & $05: 39: 17.0$ & 30.89 & 78.32 & 10 & 2.2 & $7.6 \times 10 \mathrm{e} 13$ & 381 & 10.7 \\
14 & $7 / 23 / 2007$ & $06: 33: 20.8$ & 30.89 & 78.27 & 8.6 & 2.0 & $2.4 \times 10 \mathrm{e} 14$ & 459 & 3.5 \\
15 & $7 / 23 / 2007$ & $07: 57: 05.4$ & 30.91 & 78.30 & 8.8 & 2.3 & $6.5 \times 10 \mathrm{e} 13$ & 430 & 2.5 \\
16 & $7 / 23 / 2007$ & $08: 00: 00.3$ & 30.88 & 78.30 & 7.8 & 2.3 & $7.12 \times 10 \mathrm{e} 13$ & 501 & 1 \\
17 & $7 / 23 / 2007$ & $09: 08: 08.1$ & 30.91 & 78.32 & 9.9 & 2.3 & $1.7 \times 10 \mathrm{e} 13$ & 434 & 7.03 \\
18 & $7 / 23 / 2007$ & $20: 19: 59.5$ & 30.85 & 78.26 & 9.8 & 1.2 & $7.5 \times 10 \mathrm{e} 13$ & 366 & 23.4 \\
\hline
\end{tabular}




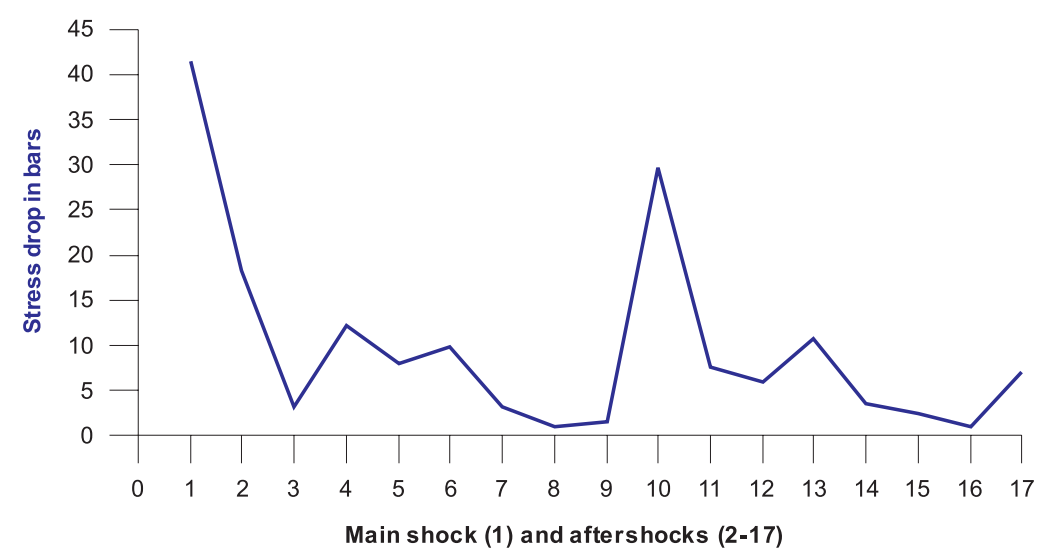

Figure 3. Variation of stress drop for the main shock and well located aftershocks.

\section{Results and discussion}

The present work is based on analyses of the data recorded by broadband seismograph stations consisted of a total of 11-telemetered Trillium $240 \mathrm{~s}$ seismometers. In principle, it is possible to use empirical Green functions to separate fault and auxiliary plane and to estimate parameters of the extended source, slip and source time (rise time) of main and aftershock. The aftershocks are very close to the main shock. The spectral analysis has not been performed because it is more important and feasible for aftershocks. The seismograms are processed in full frequency band which is a very difficult task. The inversion of many source parameters like strike, dip, rake, rise time, rupture velocity and even the slip distribution are obtained by applying forward modelling using geometric ray method for full band seismograms. In the different stages of the computation of synthetic accelerograms at the time of performing waveform modelling are taken into account of several parameters, such as location of the point of rupture initiation or focus, rupture velocity, rise time and distribution of slip amplitude on the fault plane. These are the most critical parameters which dictate the generation of synthetic seismograms. The degree of matching between the observed and synthetic seismogram depends on accurate selection of these parameters.

\subsection{Source parameters from spectral studies}

The seismic moment of the main shock determined from the displacement spectra is $4.16 \times 10^{16} \mathrm{Nm}$ with source radius of $1.76 \mathrm{~km}$. The seismic moment of the aftershocks vary from $1.7 \times 10^{13} \mathrm{Nm}$ to $6.6 \times 10^{14} \mathrm{Nm}$ (table 1) with the variation of source radii from 0.35 to $0.54 \mathrm{~km}$. The stress drop obtained for the main event using spectral analysis of Brune's circular model is 41.6 bar that is close
Table 2. Other source parameters of Kharsali earthquake of 22 July 2007 obtained by waveform modelling.

\begin{tabular}{cll}
\hline Sl. no. & \multicolumn{1}{c}{ Parameter } & \multicolumn{1}{c}{ Value } \\
\hline 1 & Length of the fault & $10 \mathrm{~km}$ \\
2 & Width of the fault & $6 \mathrm{~km}$ \\
3 & Dip of the fault & $14^{\circ}$ \\
4 & Strike of the fault & $\mathrm{N} 279^{\circ}$ \\
5 & Rise time & $0.28 \mathrm{~s}$ \\
6 & Rupture velocity & $1.7 \mathrm{~km} / \mathrm{s}$ \\
7 & Slip angle & $117^{\circ}$ \\
8 & Rupture model & Circular rupture \\
9 & Average slip & $57 \mathrm{~cm}$ \\
10 & Maximum slip & $97 \mathrm{~cm}$ \\
\hline
\end{tabular}

to the specified value of 30 bar for the interplate region of Himalayan tectonics. The stress drop obtained for the aftershocks varies from 1 to 30 bar (table 1 and figure 3 ). The calculated stress drops in the region are low, which can be understood with the partial stress drop model (Brune 1970; Brune et al 1986). These earthquakes arise as a consequence of strain accumulation due to the adjustments undergoing in the region. The low value of stress drops at shallow depths indicates that the constituent rock mass of the region cannot withstand large amount of accumulated strain energy. Figure 3 shows the variation of stress drop for the main shock and well located aftershocks. The early aftershocks occurring at greater depth near and below the main shock have caused higher stress drop in comparison to the later aftershocks occurring at shallow depth in the northwest side. It may be explained in terms of consolidation of lithological setup. The formation at greater depth has more stress accumulating strength with decrease in brittle strength and increase in the ductility. Therefore, the earthquakes of higher magnitude are expected to occur at greater depth in the Himalaya region, the similar facts has also been given by $\mathrm{Ni}$ and Barzangi (1984). 

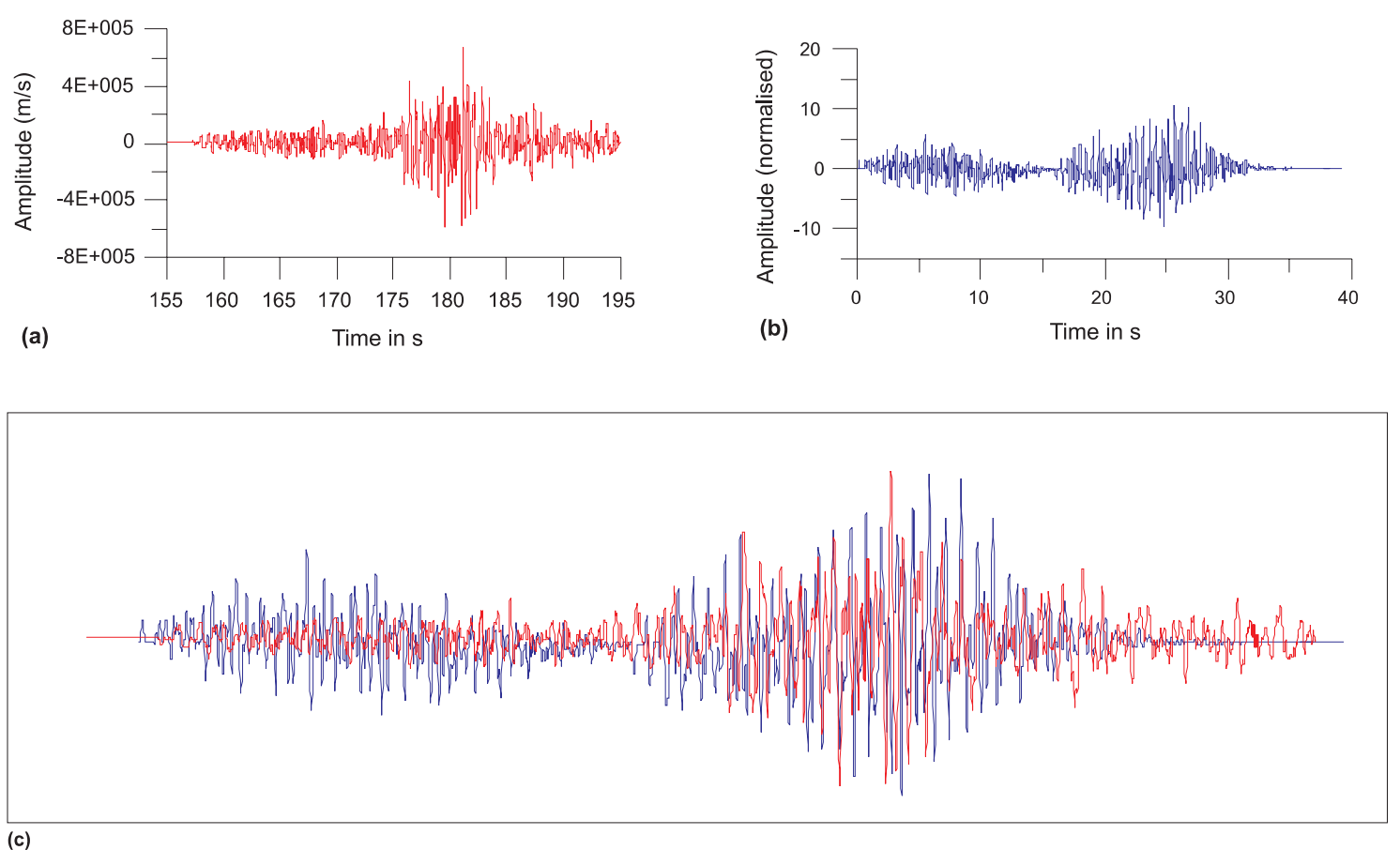

Figure 4. Station Tapovan E-W component seismograms: (a) observed, (b) synthetic seismogram, and (c) superimposed seismograms (40 s each).
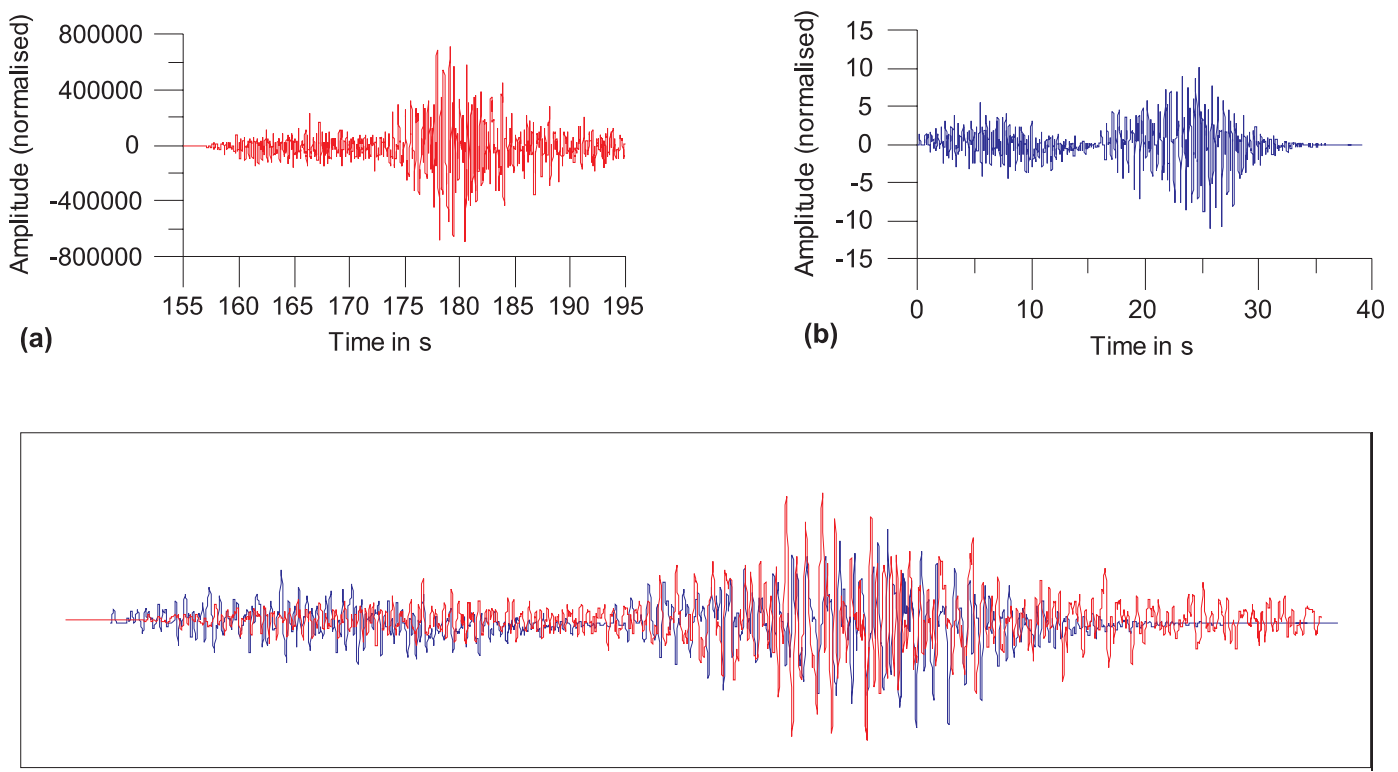

(c)

Figure 5. Station Tapovan N-S component seismograms: (a) observed, (b) synthetic seismogram, and (c) superimposed seismograms (40 s each).

\subsection{Source parameters from waveform modelling}

The seismograms have been synthesized at all the eleven sites. The locations of these sites along with the epicenter of the earthquake have been shown in figure 1 . The source parameters given in table 2 are obtained on the basis of comparison of synthetic seismograms with the observed ones. Figures 4, 5 and 6 show the comparison of seismograms for seismic station Tapovan for the ground motions in E-W, N-S and vertical directions, respectively and figures 7 and 8 show the comparison of $\mathrm{P}-$ and $\mathrm{S}$ wave spectra for Tapovan station, respectively. 

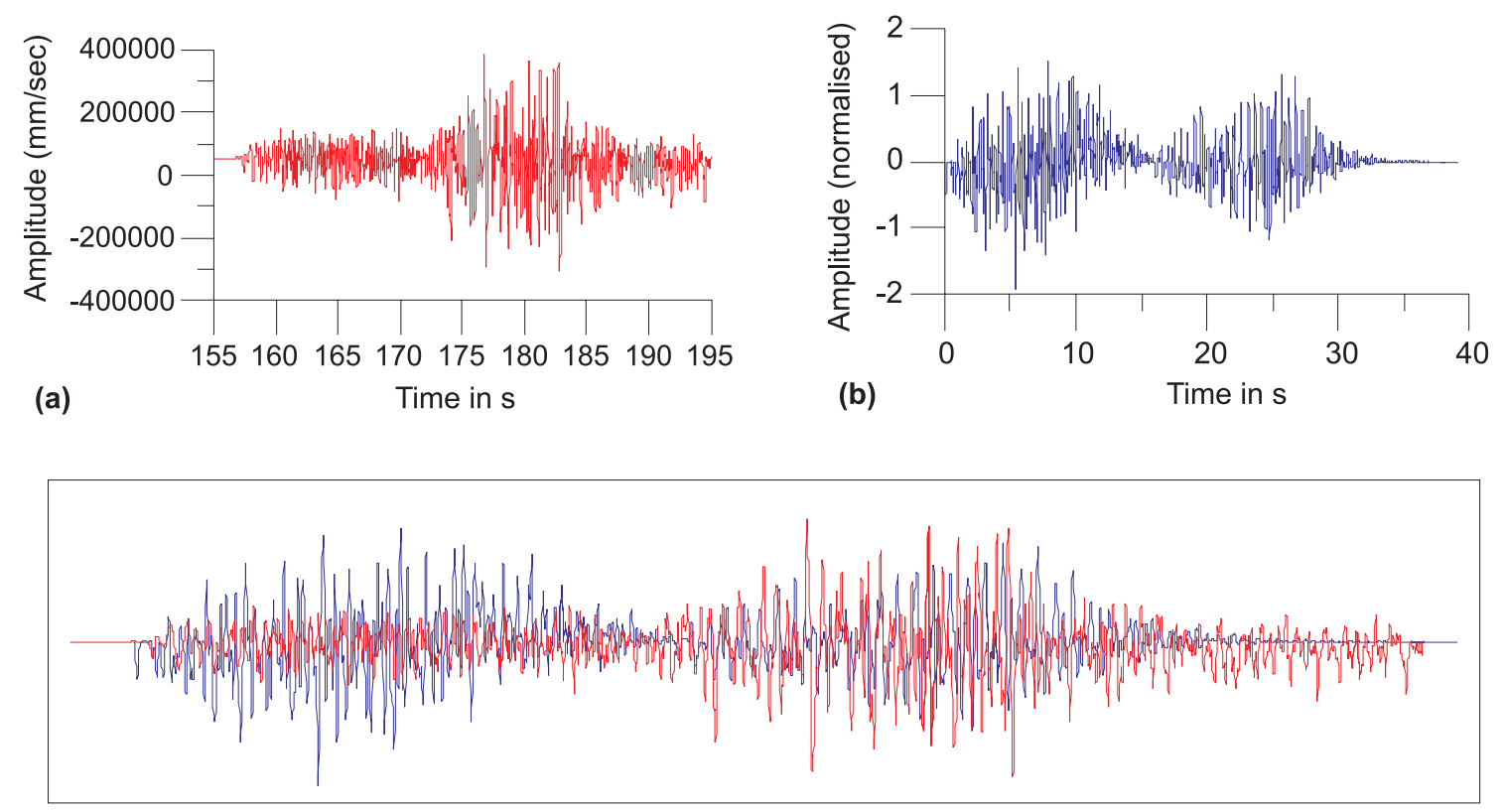

(c)

Figure 6. Station Tapovan vertical component seismograms: (a) observed, (b) synthetic seismogram, and (c) superimposed seismograms (40 s each).

These source parameters arrived at in this study were obtained after numerous numerical simulations. It has been found that slip distribution plays an important role in synthesizing waveforms. The distribution of slip (Wald et al 1991) over the fault can vary both in amount and direction. There are regions on the fault where large slip might occur which corresponds to asperities. Regions of small slip are found to be close to regions of aftershock activity. Some details of this variability of slip distribution over the fault plane for the Kharsali earthquake is shown in figure 9. The distribution of slip amount on the fault plane show two regions having large concentration of high slip amplitude. The centers of these regions lie at times $2.34 \mathrm{~s}$ and $3.74 \mathrm{~s}$ after the initiation of rupture. The point of rupture initiation (i.e., the focus) lies at a depth of $10 \mathrm{~km}$ from the surface of the earth and is situated at a point on the fault plane lying at a distance of $7 \mathrm{~km}$ in the strike direction and $2 \mathrm{~km}$ in the up-dip direction.

A close examination of comparison of observed and synthetic seismograms match fairly for seven stations (Kotkhai, Chakrata, Gaurikund, Tapovan, Nahan, Adibadri and Ghuttu). The match is observed to be the best at Tapovan recording station. A good number of peaks lie close to each other. On comparing source parameters of the Kharsali earthquake with the source parameters of $M$ 6.5, 1991 Uttarkashi earthquake (Yu et al 1995) and Chamoli earthquake (Joshi 2003) it can be said that the region continues to exhibit low angle thrust mechanism rupture sources occurring at mid-crust depth.

The slip distribution over the fault indicates that the area of the fault which contributes to the large amplitudes of recorded seismograms is a small fraction of the total area. On this portion of the fault the slip amplitudes are high. These regions of the fault have been termed as asperities. Most of the seismic wave energy takes place from such asperities. The complexity of observed seismograms depends on the size and number of such asperities.

A contour map of the slip distribution over the fault shows two asperities (figure 9). These asperities occurred at $2.44 \mathrm{~s}$ and $3.78 \mathrm{~s}$ from the initiation of rupture. The two asperities are nearly contiguous. The larger asperity at $3.78 \mathrm{~s}$ lies to the west of the hypocenter and contributes larger amplitudes in the recorded seismograms. The largest value of slip is $97 \mathrm{~cm}$ and the average slip is $57 \mathrm{~cm}$. The total area of the fault plane is $60 \mathrm{~km}^{2}$ of which the smaller asperity covers $2 \mathrm{~km}^{2}$ and the larger asperity covers $6 \mathrm{~km}^{2}$. The rest of the $52 \mathrm{~km}^{2}$ does not contribute much to the radiated energy. The two asperities on the fault plane occupy those regions in which the slip amplitude is more than $25 \mathrm{~cm}$. The rupture front takes about $2.92 \mathrm{~s}$ to cover this asperity which is also found to be the duration of those portions of the recorded seismograms where amplitudes are high, especially at those stations which are nearer to the epicenter like Kharsali and Gaurikund. 

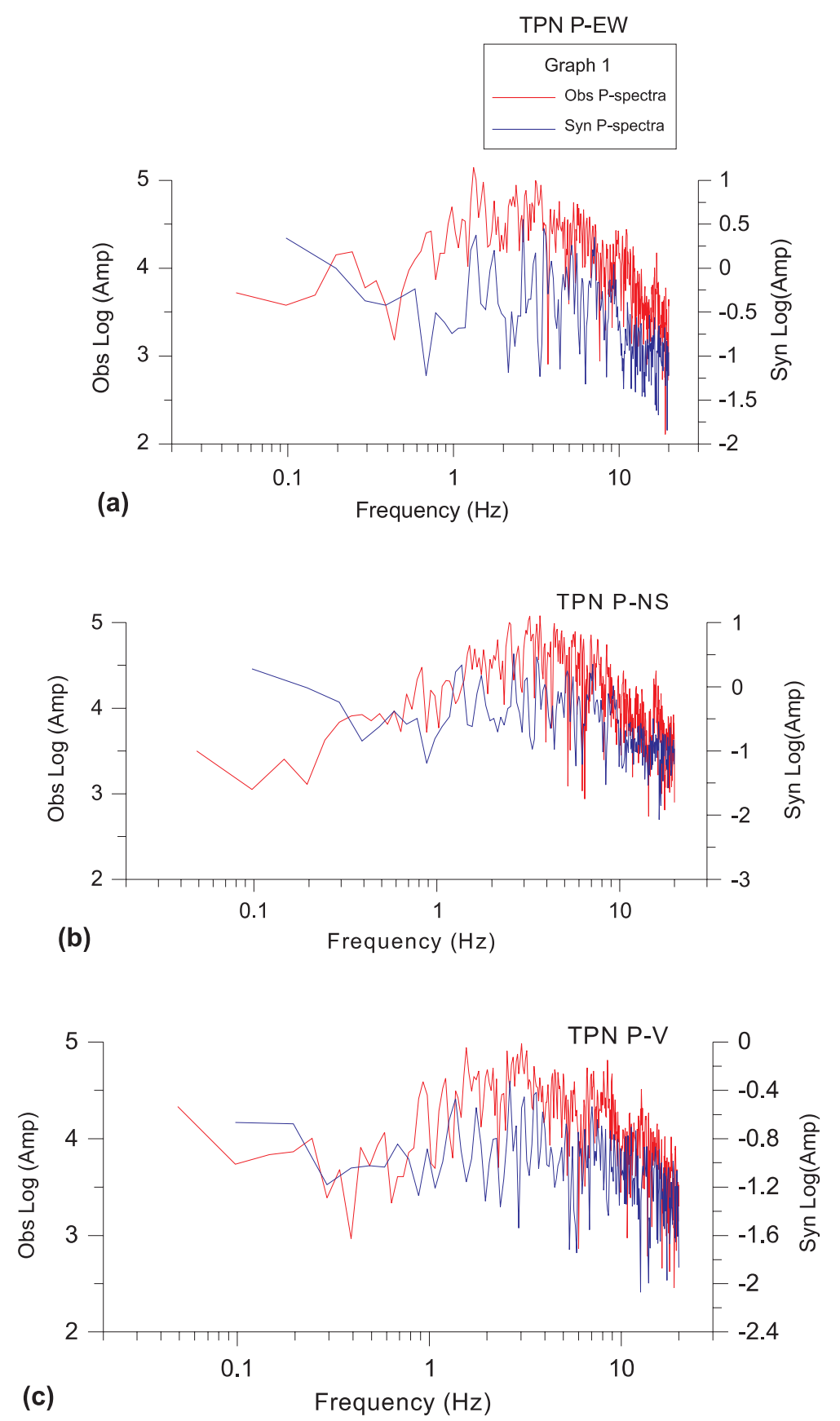

Figure 7. Comparison of $\mathrm{P}$ wave spectrum for Tapovan station of components. (a) East-west (EW), (b) north-south (NS), and (c) vertical (V).

Our study helps proper characterization of source using waveform modelling of the Kharsali earthquake $(M 4.9)$ because of better constraints on location of rupture initiation, rupture velocity, rise time and distribution of slip amplitude on the fault. Estimates of source parameters and their analyses support the idea that it is structural heterogeneity which can initiate the brittle failures since earthquake generating processes are closely associated with nature and extent of asperities that cover only a part of the total area of the causative fault plane $(10 \%)$ in the present study. However, detailed seismic imaging of these two asperities can be corroborated with structural heterogeneities associated with causative fault to understand how seismogenesis is influenced by strong or weak structural barriers in the region (Mishra and Zhao 2004; Mishra et al 2008; Kumar et al 2009).

\subsection{Relevance of the study}

Four great earthquakes $M$ 8.7, 8.6, 8.4 and 8.7 have occurred in the Himalaya region in India at different parts in the last two hundred years period 

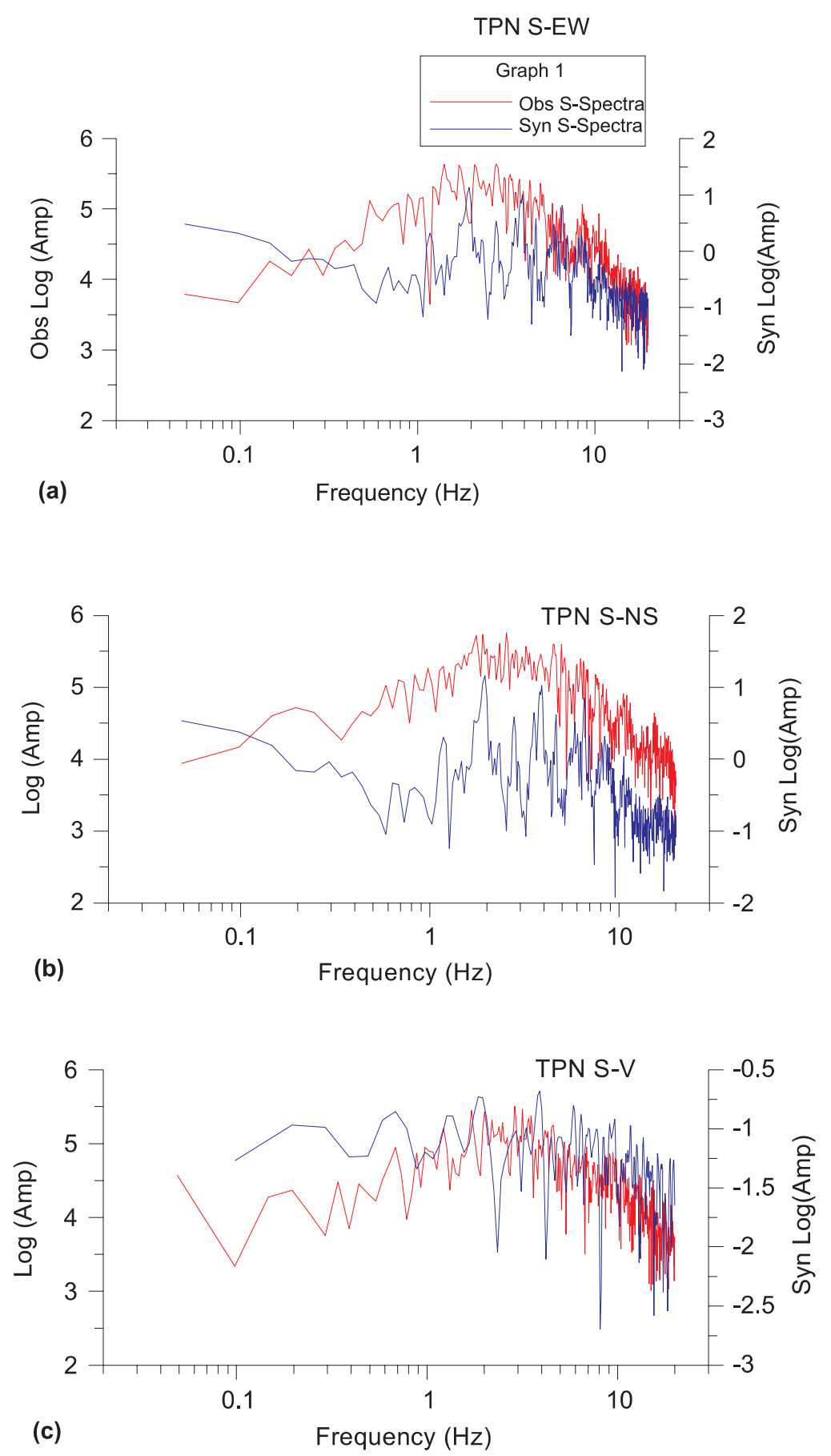

Figure 8. Comparison of S wave spectrum for Tapovan station of components. (a) East-west (EW), (b) north-south (NS), and $(\mathbf{c})$ vertical $(\mathrm{V})$.

(Richter 1958). In these earthquakes, the Kangra Earthquake ( $M$ 8.6) of 1905 , occurred in western Himalaya and its meizoseismal area was reported to be extended into Garhwal Himalaya the region to the east of 1905 Kangra earthquake and west of 1934 Bihar earthquake ( $M$ 8.4) have been recognized as $700 \mathrm{~km}$ long seismic gap (Bilham and Gaur 2000). So far this region has recorded any large earthquake and from long back being treated as potential site of its occurrence. Therefore, the recent earthquake recorded by high dynamic range digital broadband seismographs is a critical evaluation to elaborate the ongoing earthquake processes in this region. We have obtained detailed information using observed and theoretical approach which is helpful for evaluating source processes which would be useful for developing seismotectonic model. This is a step towards seismic risk 


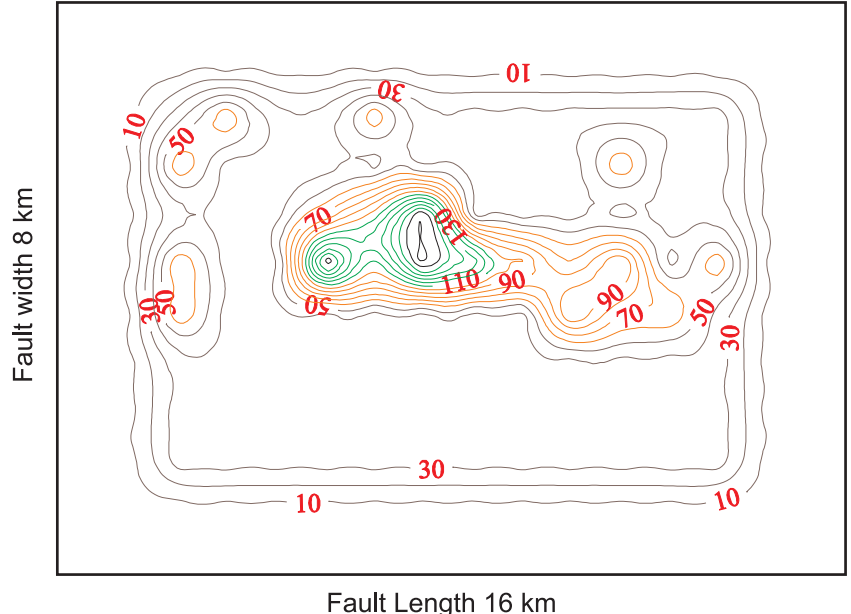

Figure 9. Slip distribution model for Kharsali earthquake. Depth contours in $\mathrm{km}$ at intervals of $20 \mathrm{~km}$.

mitigation in the region due to a possible great magnitude earthquake. This is a strong motivation for investing the ongoing seismicity and earthquake source process in the Garhwal Himalaya.

Further, there are number of perennial rivers originating from Garhwal Himalaya offering vast potential for irrigation and generation of hydroelectric power. Multipurpose river valley schemes have been conceived for the region. Some of them have been completed and many are in progress. The power generation at $260 \mathrm{~m}$ high earth and rock fill Tehri Dam on the Bhagirathi river is operational now.

The present work is a step towards seismic risk mitigation in the region due to a possible great magnitude earthquake. This is a strong motivation for investing the ongoing seismicity and earthquake source process in the Garhwal Himalaya.

\section{Acknowledgements}

The authors are grateful to the Director, Wadia Institute of Himalayan Geology, Dehradun for his encouragement. Our sincere thanks to the Department of Science and Technology and Ministry of Earth Science, New Delhi for generous financial assistance. We thank Dr O P Mishra, and the other anonymous reviewer for their support and comments. The authors are also thankful to Dr Pawan Dewangan, Associate Editor for his suggestions.

\section{References}

Auden J B 1934 The geology of the Krol belt rec; Geol. Surv. India 67 357-454.

Ben-Menahem Ari and Singh Sarva Jit 1981 Seismic waves and sources (New York Inc.: Springer-Verlag) 1108.
Bilham R and Gaur V K 2000 Geodetic contributions to the study of seismotectonics in India; Curr. Sci. 79(9) $1259-1269$.

Brune J N 1970 Tectonic stress and spectra of seismic shear waves from earthquakes; J. Geophys. Res. 75 4997-5009.

Brune J N, Fletcher J, Vernon F, Harr L, Hanks T and Berger J 1986 Low stress-drop earthquakes in light of new data from the ANZA, California telemetered digital array; Geophysics Monogram, American Geophysical Union 37 237-244.

Dewey J F and Bird J M 1970 Mountain belt and the new global tectonics; J. Geophys. Res. 75 2625-2647.

Douglas B M and Ryall A 1972 Spectral characteristics and stress drop for microearthquakes near Fairview Peak, Nevada; J. Geophys. Res. 77 351-359.

Gansser A 1964 Geology of the Himalaya (New York: Inter Science) 298.

Hanks T C and Wyss M 1972 The use of body wave spectra in the determination of seismic-source parameters; Bull. Seismol. Soc. Am. 62 561-589.

Haskell N A 1969 Elastic displacements in the near field of a propagating fault; Bull. Seismol. Soc. Am. 81(5) 1540-1572.

Heim A and Gansser A 1939 Central Himalaya, geological observation of the Swiss Expedition 1936; Hindustan Publication Corporation (India), Delhi, 1975 edn, Mem. Soc. Helv. Sci. Nat. 73 1-245.

Ichinose G A, Smith K D and Anderson J G 1997 Source parameters of the 15 November 1995 Border Town, Nevada, Earthquake sequence; Bull. Seis. Soc. Am. 87(3) $652-667$

Joshi A 2003 Predicting strong motion parameters for the Chamoli Earthquake of 28th March 1999, Garhwal Himalaya, India from simplified finite fault model; J. Seismol. 7 1-17.

Keilis-Borok V I 1959 An estimation of the displacement in earthquake source and source dimensions; Ann. Geofos 12 205-214.

Keiiti Aki 1968 Seismic displacement near a fault; J. Geophys. Res. 73 5359-5376.

Keiiti Aki and Richards Paul G 1980 Quantitative seismology: Theory and Methods, W.H. Freeman and Company, San Francisco 1 \& 2932.

Khattri K N, Zeng Y, Anderson J G and Brune J 1994 Inversion of strong motion waveforms of source slip function of 1991 Uttarkashi earthquake, Himalaya; J. Him. Geol. 5(2) $163-191$.

Khattri K N 1992a Local seismic investigations in the Garhwal-Kumaon Himalaya; Geol. Soc. India Memoir 23 45-66.

Khattri K N 1992b Seismological investigations in North Eastern region of India; Geol. Soc. India Memoir 275-302.

Khattri K N and Tyagi A K 1983 Seismicity patterns in the Himalayan plate boundary and identification of the areas of high seismic potential; Tectonophys. 96 281-297.

Kumar Naresh, Sharma Jyoti, Arora B R and Mukhopadhyay Sagarika 2009 Seismotectonic model of the KangraChamba sector of Northwest Himalaya: Constraints from joint hypocenter determination and focal mechanism; Bull. Seismol. Soc. Am. 99(1) 95-109.

Kumar B A, Ramana D V, Kumar C P, Rani V S, Shekhar M, Srinagesh D and Chadha R K 2006 Estimation of source parameters for 14th March 2005 earthquake of Koyana-Warna region; Curr. Sci. 91(4) $526-530$

Lee and Stewart 1981 Principles and applications of microearthquake networks; Academic Press, 293p. 
Mikumo T and Miyatake T 1987 Numerical modeling of realistic fault rupture process 109-146; In: Seismic strong motion synthetics (ed.) Bolt B A, Academic Press Inc., $328 \mathrm{p}$.

Mishra O P and Zhao D 2004 Seismic evidence for dehydration embrittlement of the subducting Pacific slab; Geophys. Res. Lett. 31 L09610, doi: 10.1029/2004GL019489.

Mishra O P, Zhao D and Wang Z 2008 The Genesis of the 2001 Bhuj, India Earthquake $\left(M_{w} 7.6\right)$ A puzzle for Peninsular India?; Indian Minerals 61(3-4) \& 62 (1-4) 149-170.

Ni J and Barazangi M 1984 Seismotectonics of the Himalayan collision zone: Geometry of the underthrusting Indian plate beneath the Himalaya; J. Geophys. Res. 89 1147-1163.

Paul Ajay and Pant P D 2003 Seismic hazard estimation in northeastern Kumaun Himalayas; J. Geol. Soc. India 61 477-482.

Prochazkova D 1980 Determination of source parameters; In: Development in solid earth geophysics (eds) Bisztricsany E and Szeidonitz G Y, Proc. 17th Assembly of the Europian Seismological Commission, 24-29 August, Elsevier Science.

Richter C F 1958 Elementary seismology (San Fransisco: W. H. Freeman and Co) 768p.
Singh V N and Mittal Abha 2005 Synthetic accelerograms for two Himalayan earthquakes using convolution; Curr. Sci. 88(8) 1289-1297.

Sharma M L and Wason H R 1994 Occurrence of low stress drop earthquakes in the Garhwal Himalaya region; Phys. Earth Planet. Int. 85 265-272.

Valdiya K S 1988 Geology and natural environment of the Nainital Hills, Kumaun Himalaya, 155p.

Wald D J, Donald V Helmberger and Thomas H Heaton 1991 Rupture model of the 1989 Loma Prieta earthquake from the inversion of strong motion and broad band and teleseismic data; Bull. Seismol. Soc. Am. 81(5) $1540-1572$.

Wyss M and Hanks T C 1972 The source parameters of the San Fernando earthquake inferred from teleseismic body waves; Bull. Seismol. Soc. Am. 62 591-602.

$\mathrm{Yu}$ G, Khattri K N, Anderson J G, Brune J N and Zeng Y 1995 Strong ground motion from the Uttarkashi, Himalaya, India, Earthquake: Comparison of observations with synthetics using the composite source model; Bull. Seismol. Soc. Am. 85(1) 31-50.

Zhao W J, Nelson K D and Project INDEPTH Team 1993 Deep seismic reflection evidence for continental underthrusting beneath southern Tibet; Nature $\mathbf{3 3 6}$ $557-559$. 